\title{
A New Reactive-Power Sharing Scheme for Two Inverter-Based Distributed Generations with Unequal Line Impedances in Islanded Microgrids
}

\author{
Jae-Hyuk Kim, Yoon-Seok Lee, Hyun-Jun Kim and Byung-Moon Han * \\ Department of Electrical Engineering, Myong-ji University, 116 Myongji-ro, \\ Yongin-si, Gyeonggi-do 449-728, Korea; pwm0125@naver.com (J.-H.K.); lys1909@hanmail.net (Y.-S.L); \\ inverter1112@naver.com (H.-J.K.) \\ * Correspondence: erichan@mju.ac.kr; Tel.: +82-31-330-6366
}

Received: 28 September 2017; Accepted: 5 November 2017; Published: 8 November 2017

\begin{abstract}
This paper proposes a new reactive-power sharing scheme to reduce the circulating current when two inverter-based distributed generations (DGs) operate in parallel through unequal line impedances in an islanded microgrid. If the terminal voltages of the two DGs are not equal due to the unequal line impedances, a circulating current due to reactive-power unbalance occurs, which increases system loss. The proposed droop control compensates the terminal voltage difference to reduce the circulating current by considering a feed-forward path of the line voltage drop. The feasibility of the proposed droop control was first verified through computer simulations, and then experiments with a hardware set-up in the lab. The experimental results were compared with the simulation results to confirm the feasibility of the proposed droop control.
\end{abstract}

Keywords: distributed generation (DG); droop control; reactive power sharing; circulating current; feed-forward path

\section{Introduction}

Distributed generations (DGs) are operated in parallel to supply large capacity electric power with high reliability and efficiency. When two or more parallel-connected DGs supply electric power to the load through unequal feeder impedances, the active and reactive powers are not shared equally in the load. Several methods have been developed to solve this unequal sharing problem [1-3].

One typical method is a master-slave control based on the communication link. The master control normally operates in voltage control mode, while the slave control operates in current control mode. The master-slave control shows very effective performance in load sharing despite the unequal line impedances. It has advantages of simple system design and easy application [4-7]. However, the electric power must be measured in real time and sent to the central controller through a communication link, so due to communication delays or errors, overcurrent and mal-operation may occur. If a failure occurs in the master controller, the entire system will be shut down.

In order to ensure stability and economical operation, the active and reactive powers of DGs should be shared simultaneously. Droop control can be used to achieve the power sharing without a communication link, which was used in the parallel operation of synchronous generators [8-12]. In the droop control the frequency is changed according to the active power, while the voltage is changed according to the reactive power. The system reliability can be enhanced because no communication link is required, however, circulating currents can be generated if the reactive powers are not shared equally due to the unequal DG output impedances [13-20].

Many studies have been carried out to solve the reactive power sharing problem by applying larger V-Q droop coefficient and inserting virtual inductor in control [21-23]. In the case of applying 
a larger droop coefficient, the output voltage range permitted for the system will be exceeded although the dynamic characteristics will be improved and reactive power sharing will be obtained. In case of inserting virtual inductor, the sine wave output current is differentiated and multiplied by virtual inductance. Thus, if the output current is mixed with high frequency noises, noise amplification will occur which could deteriorate the control stability.

An improved droop control scheme was proposed for reactive power sharing in islanded microgrids, which uses the error reduction operation by low-bandwidth synchronization signal and the voltage recovery operation to compensate the voltage reduction due to the error reduction operation [11,12]. A secondary voltage control scheme was proposed for reactive power sharing in islanded microgrid [24]. This scheme inserts an integral term into the voltage droop function in which the voltage compensation signal from the secondary voltage control is utilized as the reactive power reference. However, both schemes require communication link for supplying the low-bandwidth reference signal.

In references $[25,26]$, the line impedance influence on the control scheme for two parallel operated inverters was described. This paper proposes an improved droop control scheme for reactive power sharing in two parallel-connected DGs through unequal line impedances, in which the voltage drop due to the line impedance is compensated by feed-forwarding. Since the proposed droop control requires an accurate estimation for the line impedance, a new estimation method for the line impedance was proposed and its performance was verified by computer simulation. There are several active methods to estimate the line impedance with software approaches [27-29]. One typical method is to inject the harmonic current and to measure the corresponding voltage and current of grid for estimating the line impedance. However, the performance of this method is affected by the background harmonic component. Another method is to measure the grid voltage and current at two different operating points which are changed by adjusting the active and reactive powers [30]. This paper proposes a new estimation method for the line impedance in which the slope of V-Q line characteristic is measured by small-step changing of the reactive power until the estimated value is equal to the actual value.

In this paper the concept of proposed droop control is described in Section 2. The estimation of line impedance using the droop control is explained in Section 3. The voltage control design for inverter-based DG is described in Section 4. The simulation results for parallel-connected DGs with unequal line impedances are described in Section 5. Finally, the experimental results for parallel-connected DGs with unequal line impedances are described in Section 6.

\section{Proposed Droop Control}

\subsection{Droop Control Concept}

Figure 1 shows a simple equivalent circuit of DG connected to the AC grid. The principle of general droop control is that the magnitude and phase of the DG output voltage are used for the control of active and reactive powers.

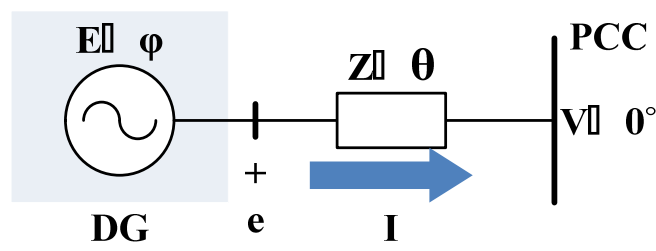

Figure 1. Equivalent circuit for distributed generation (DG) connected to an AC grid.

The $\omega$-P droop and V-Q droop controls can be expressed by Equations (1) and (2):

$$
\omega=\omega^{*}-k_{p} P
$$




$$
\mathrm{E}=\mathrm{E}^{*}-\mathrm{k}_{\mathrm{q}} \mathrm{Q}
$$

where, $\omega$ and E represent the frequency and magnitude of the DG output voltage, respectively, $\omega^{*}$ and $\mathrm{E}^{*}$ represent the nominal frequency and voltage at the point of common connection (PCC), respectively, and $\mathrm{k}_{\mathrm{p}}$ and $\mathrm{k}_{\mathrm{q}}$ are the droop coefficient for frequency and voltage control, respectively.

\subsection{Reactive Power Sharing}

The output voltage of two parallel-operated DGs should be same or proportional when the droop control is applied. However, if the line impedances are not equal, reactive power sharing problem occurs.

Figure 2 shows an equivalent circuit for two parallel-operated DGs [19]. If the circuit is numerically examined on the $\mathrm{d}-\mathrm{q}$ rotational coordinate, the V-Q droop control can be expressed by Equation (3):

$$
\mathrm{E}_{\mathrm{di}}=\mathrm{E}_{\mathrm{di}}^{*}-\mathrm{k}_{\mathrm{qi}} \mathrm{Q}_{\mathrm{i}} \mathrm{E}_{\mathrm{qi}}=\mathrm{E}_{\mathrm{qi}}^{*}
$$

where, $\mathrm{E}_{\mathrm{di}}$ and $\mathrm{E}_{\mathrm{qi}}$ are the DG output voltage on the $\mathrm{d}-\mathrm{q}$ synchronous coordinate, respectively, and $\mathrm{E}_{\mathrm{di}}^{*}$ and $E_{q i}^{*}$ are the generated $d-q$ reference voltage of $D G$ for $i=1,2$, respectively. The value of $E_{d i}^{*}$ is equal to the nominal value of $E_{i}$ and the value of $E_{q i}^{*}$ is equal to 0 because the nominal voltage $E_{i}$ is located in parallel with the d-axis.

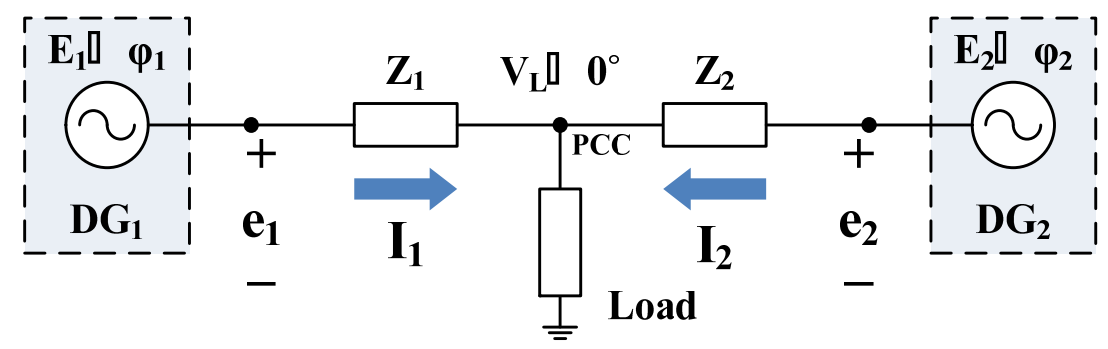

Figure 2. Equivalent circuit for two parallel operated DGs.

In order to analyze the reactive power sharing, equivalent circuits on the $d$-q rotational coordinate are derived by the V-Q droop equation shown in Equation (3). Figure 3 shows the $\mathrm{d}$-q equivalent circuits for the DG connected to the load neglecting the line impedance.

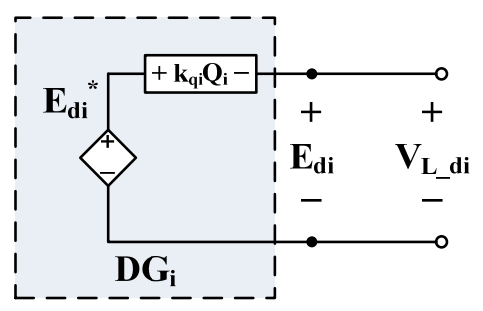

(a)

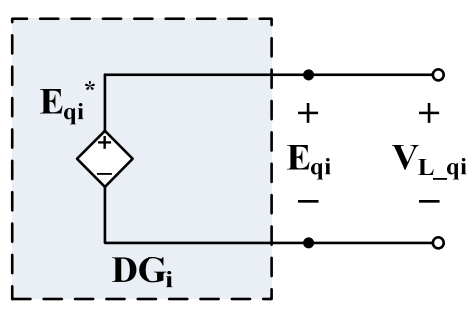

(b)

Figure 3. $d-q$ equivalent circuits for DGs connected to load neglecting the line impedance: (a) d-axis;

(b) q-axis.

The reference DG output voltages on the $\mathrm{d}-\mathrm{q}$ synchronous coordinate are expressed by Equation (4) if the line impedance is neglected:

$$
\begin{gathered}
\mathrm{E}_{\mathrm{di}}^{*}=\mathrm{k}_{\mathrm{qi}} \mathrm{Q}_{\mathrm{i}}+\mathrm{V}_{\mathrm{L}_{\mathrm{di}}}=\mathrm{k}_{\mathrm{qi}} \mathrm{Q}_{\mathrm{i}}+\mathrm{E}_{\mathrm{di}} \\
\mathrm{E}_{\mathrm{qi}}^{*}=\mathrm{V}_{\mathrm{L}_{\_} \mathrm{qi}}=\mathrm{E}_{\mathrm{qi}}
\end{gathered}
$$


where, $\mathrm{V}_{\mathrm{L}_{-} \mathrm{di}}$ and $\mathrm{V}_{\mathrm{L}_{-} \mathrm{qi}}$ represent the $\mathrm{d}-\mathrm{q}$ components of load voltage, respectively. The above equation can be rearranged with respect to $\mathrm{V}_{\mathrm{L}_{-} \mathrm{di}}$ and $\mathrm{V}_{\mathrm{L}_{-} \mathrm{q} i}$ as shown in Equation (5):

$$
\mathrm{V}_{\mathrm{L}_{-} \mathrm{di}}=\mathrm{E}_{\mathrm{di}}^{*}-\mathrm{k}_{\mathrm{qi}} \mathrm{Q}_{\mathrm{i}} \mathrm{V}_{\mathrm{L}_{-} \mathrm{qi}}=\mathrm{E}_{\mathrm{qi}}^{*}
$$

Assuming that the $\mathrm{d}$-q rotational coordinate is set on the load voltage, the d-component load voltage $\mathrm{V}_{\mathrm{L}_{-} \text {di }}$ is equal to the load voltage $\mathrm{V}_{\mathrm{L}_{-} \mathrm{i}}$ and the $\mathrm{q}$-component load voltage $\mathrm{V}_{\mathrm{L}_{-} q \mathrm{i}}$ is equal to zero as shown in Equation (6):

$$
\begin{gathered}
\mathrm{V}_{\mathrm{L}_{\_} \mathrm{di}}=\mathrm{E}_{\mathrm{di}}^{*}-\mathrm{k}_{\mathrm{qi}} \mathrm{Q}_{\mathrm{i}}=\mathrm{V}_{\mathrm{L}_{\_} \mathrm{i}} \\
\mathrm{V}_{\mathrm{L}_{-} \mathrm{qi}}=\mathrm{E}_{\mathrm{qi}}^{*}=0
\end{gathered}
$$

Equation (7) is obtained to express the relationship between the load voltage and the reactive power:

$$
\mathrm{V}_{\mathrm{L}_{-} \mathrm{i}}=\mathrm{E}_{\mathrm{di}}^{*}-\mathrm{k}_{\mathrm{qi}} \mathrm{Q}_{\mathrm{i}}
$$

Therefore, if the line impedance is negligible, the reactive power sharing is determined only by the variation of load voltage. No issue occurs on the reactive power sharing between two parallel-operated DGs, which can confirmed by Equation (8):

$$
\mathrm{Q}_{\mathrm{i}}=\frac{\mathrm{E}_{\mathrm{di}}^{*}-\mathrm{V}_{\mathrm{L} \_\mathrm{i}}}{\mathrm{k}_{\mathrm{qi}}}
$$

However, if line impedance is involved, the reactive power sharing is not determined by Equation (8). Figure 4 shows the d-q equivalent circuits for the DG connected to the load considering the line impedance.

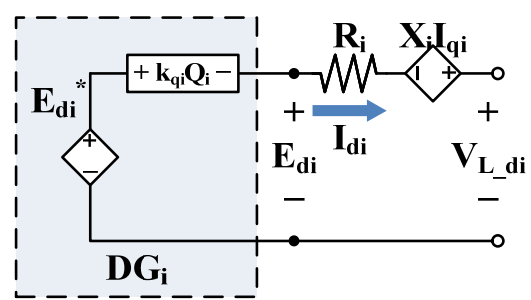

(a)

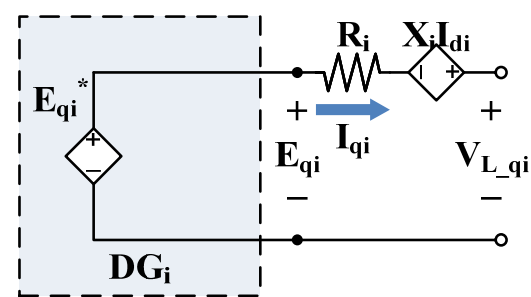

(b)

Figure 4. d-q equivalent circuits for DG connected to load considering line impedance: (a) d-axis; (b) q-axis.

The voltage relationship in the above equivalent circuits can be expressed by Equation (9):

$$
\mathrm{E}_{\mathrm{di}}^{*}=\mathrm{k}_{\mathrm{qi}} \mathrm{Q}_{\mathrm{i}}+\mathrm{R}_{\mathrm{i}} \mathrm{I}_{\mathrm{di}}-\mathrm{X}_{\mathrm{i}} \mathrm{I}_{\mathrm{qi}}+\mathrm{V}_{\mathrm{L}_{-} \mathrm{di}} \mathrm{E}_{\mathrm{qi}}^{*}=\mathrm{R}_{\mathrm{i}} \mathrm{I}_{\mathrm{qi}}-\mathrm{X}_{\mathrm{i}} \mathrm{I}_{\mathrm{di}}+\mathrm{V}_{\mathrm{L}_{-} \mathrm{qi}}
$$

where, $I_{d i}$ and $I_{q i}$ are the $d-q$ axis currents, $R_{i}$ and $X_{i}$ are the line resistance and reactance respectively.

Assuming that the power angle between the DG output voltage and the load voltage is very small, the q-axis voltage can be neglected as shown in Equation (10):

$$
\mathrm{E}_{\mathrm{qi}}^{*}=\mathrm{R}_{\mathrm{i}} \mathrm{I}_{\mathrm{qi}}-\mathrm{X}_{\mathrm{i}} \mathrm{I}_{\mathrm{di}}+\mathrm{V}_{\mathrm{L}_{-} \mathrm{qi}} \approx 0
$$

Equation (11) can therefore be derived from Equation (9):

$$
\mathrm{V}_{\mathrm{L}_{-} \mathrm{i}} \approx \mathrm{E}_{\mathrm{di}}^{*}-\mathrm{k}_{\mathrm{qi}} \mathrm{Q}_{\mathrm{i}}-\mathrm{R}_{\mathrm{i}} \mathrm{I}_{\mathrm{di}}+\mathrm{X}_{\mathrm{i}} \mathrm{I}_{\mathrm{qi}}
$$


and the relationship between the reactive power and the line impedance can be derived by Equation (12):

$$
\mathrm{Q}_{\mathrm{i}} \approx \frac{\mathrm{E}_{\mathrm{di}}^{*}-\mathrm{V}_{\mathrm{L}_{\_} \mathrm{i}}-\mathrm{R}_{\mathrm{i}} \mathrm{I}_{\mathrm{di}}+\mathrm{X}_{\mathrm{i}} \mathrm{I}_{\mathrm{qi}}}{\mathrm{k}_{\mathrm{qi}}}
$$

If $D_{1}$ and $D_{2}$ are connected to the load through two lines with unequal impedance, the $3 r d$ and 4th terms of Equation (12) have different values for each DG. Therefore, the reactive power sharing problem occurs between $\mathrm{DG}_{1}$ and $\mathrm{DG}_{2}$ due to the coupling effect between the line current and the line impedance.

\subsection{Proposed Droop Control}

This paper proposes a feed-forward scheme into the V-Q droop control to compensate the line voltage drop, which is directly applied on the d-q transformed state. The affection of source impedance can be reduced using decoupled active and reactive powers. In addition, the reference voltage of the $\mathrm{V}-\mathrm{Q}$ droop equation can be revised by a simple calculation.

In order to compensate the line voltage drop with feed-forward manner, Equation (13) is derived from Equation (9) by replacing the load voltage $\mathrm{V}_{\mathrm{L}_{-} \mathrm{i}}$ with the nominal voltage $\mathrm{E}_{\mathrm{i}}$ :

$$
\mathrm{E}_{\mathrm{di}}=\mathrm{E}_{\mathrm{di}}^{*}-\mathrm{k}_{\mathrm{qi}} \mathrm{Q}_{\mathrm{i}}+\mathrm{R}_{\mathrm{i}} \mathrm{I}_{\mathrm{di}}-\mathrm{X}_{\mathrm{i}} \mathrm{I}_{\mathrm{qi}} \mathrm{E}_{\mathrm{qi}}=\mathrm{E}_{\mathrm{qi}}^{*}+\mathrm{R}_{\mathrm{i}} \mathrm{I}_{\mathrm{qi}}+\mathrm{X}_{\mathrm{i}} \mathrm{I}_{\mathrm{di}}
$$

Figure 5 shows the d-q equivalent circuits derived from Equation (13). These two equivalent circuits show how the proposed method can carry out the reactive power sharing using the feed-forward compensation.

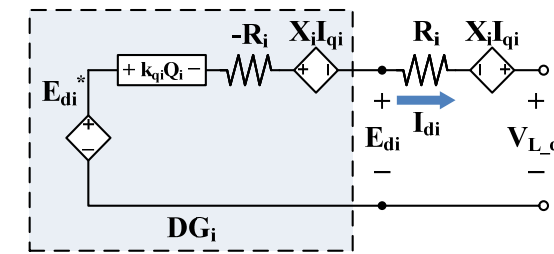

(a)

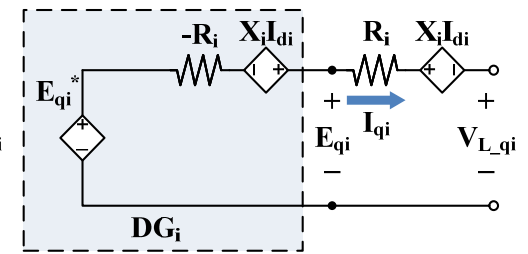

(b)

Figure 5. d-q equivalent circuits for DG connected to load with line voltage drop feed-forward compensation: (a) d-axis; (b) q-axis.

\section{Line Impedance Estimation}

Exact line impedance should be known before applying the feed-forward scheme in the proposed droop control. In this paper a new method to estimate the line resistance and reactance is derived and its performance was confirmed by simulation.

Figure 6 shows d-q equivalent circuits for estimating the line impedance. In the equivalent circuits shown in Figure 5, the line impedance for feed-forward compensation was replaced by unknown estimated line impedance $R_{e}+j X_{e}$, and the $d$-axis reference voltage is replaced by $E_{n o m}$ and the q-axis reference voltage is replaced by $0 \mathrm{~V}$.

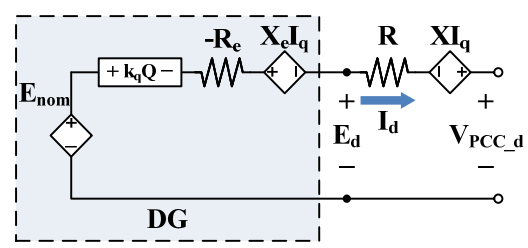

(a)

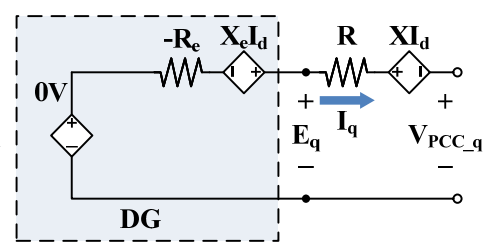

(b)

Figure 6. d-q equivalent circuits for line impedance estimation: (a) d-axis; (b) q-axis. 
From the equivalent circuits shown in Figure 6, Equation (14) can be derived:

$$
\begin{gathered}
\mathrm{V}_{\text {PCC_d }}=\mathrm{E}_{\text {nom }}-\mathrm{k}_{\mathrm{q}} \mathrm{Q}+\left(\mathrm{R}_{\mathrm{e}}-\mathrm{R}\right) \mathrm{I}_{\mathrm{d}}-\left(\mathrm{X}_{\mathrm{e}}-\mathrm{X}\right) \mathrm{I}_{\mathrm{q}} \\
\mathrm{V}_{\text {PCC_q }}=\left(\mathrm{R}_{\mathrm{e}}-\mathrm{R}\right) \mathrm{I}_{\mathrm{q}}+\left(\mathrm{X}_{\mathrm{e}}-\mathrm{X}\right) \mathrm{I}_{\mathrm{d}}
\end{gathered}
$$

Assuming that the power angle between the DG output voltage and the load voltage is very small, the q-axis voltage can be neglected as shown in Equation (15):

$$
\mathrm{V}_{\mathrm{PCC}} \approx \mathrm{E}_{\mathrm{nom}}-\mathrm{k}_{\mathrm{q}} \mathrm{Q}+\left(\mathrm{R}_{\mathrm{e}}-\mathrm{R}\right) \mathrm{I}_{\mathrm{d}}-\left(\mathrm{X}_{\mathrm{e}}-\mathrm{X}\right) \mathrm{I}_{\mathrm{q}}
$$

Using the relationship of active and reactive powers, Equation (15) can be changed into Equation (16):

$$
\mathrm{V}_{\mathrm{PCC}} \approx \mathrm{E}_{\mathrm{nom}}-\mathrm{k}_{\mathrm{q}} \mathrm{Q}+\frac{\left(\mathrm{R}_{\mathrm{e}}-\mathrm{R}\right)}{\mathrm{E}_{\mathrm{nom}}} \mathrm{P}+\frac{\left(\mathrm{X}_{\mathrm{e}}-\mathrm{X}\right)}{\mathrm{E}_{\text {nom }}} \mathrm{Q}
$$

Assuming that only reactive power is supplied by the DG, the voltage relationship with respect to $\mathrm{Q}$ is represented by Equation (17):

$$
\mathrm{V}_{\mathrm{PCC}} \approx \mathrm{E}_{\mathrm{nom}}-\mathrm{k}_{\mathrm{q}} \mathrm{Q}+\frac{\left(\mathrm{X}_{\mathrm{e}}-\mathrm{X}\right)}{\mathrm{E}_{\mathrm{nom}}} \mathrm{Q}
$$

Assuming that only active power is supplied by the DG, the voltage relationship with respect to $P$ is represented by Equation (18):

$$
\mathrm{V}_{\mathrm{PCC}} \approx \mathrm{E}_{\mathrm{nom}}-\mathrm{k}_{\mathrm{q}} \mathrm{Q}+\frac{\left(\mathrm{R}_{\mathrm{e}}-\mathrm{R}\right)}{\mathrm{E}_{\mathrm{nom}}} \mathrm{P}
$$

Figure 7a shows the principle of line reactance estimation. When the initial estimated line reactance is 0 , the load voltage variation with respect to $Q$ is expressed by Equation (17) and represented by the thin line in the bottom. As the estimated line reactance becomes larger, this thin line approaches to the solid line in the top, which represents the estimated line reactance is equal to the actual line reactance. Figure $7 \mathrm{~b}$ shows a flow chart to estimate the line reactance. First, the command value of reactive power is determined and this value is compared with the actual output reactive power. If the difference is larger than 0 , the estimated line impedance is continuously increased through iterative manner. However, if this value is smaller than 0 , the estimated line impedance is continuously decreased through iterative manner. So, the estimated line reactance that is equal to the actual line reactance can be calculated. How to set the value of $Q$ is set properly considering the accuracy of estimated value.

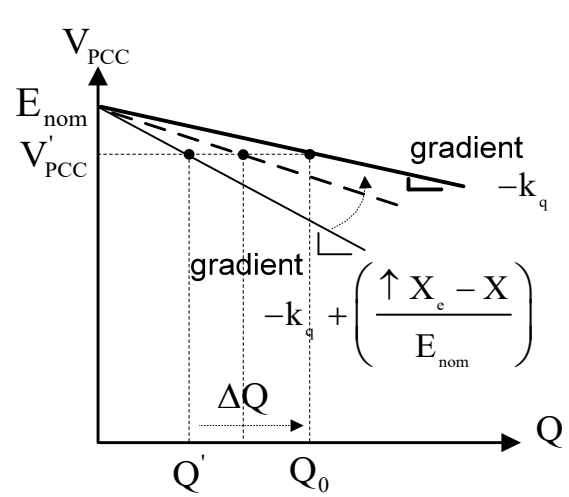

(a)

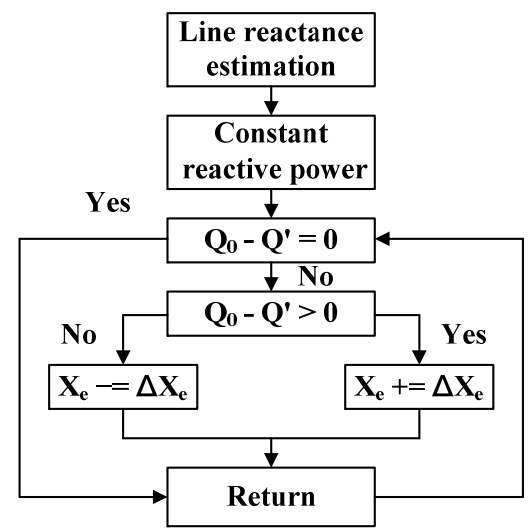

(b)

Figure 7. Algorithm for line reactance estimation: (a) Principle; (b) Estimation flow. 
Figure 8a shows the principle of line resistance estimation. When the initial estimated line resistance is 0 , the load voltage variation with respect to variable $Q$ and constant $P$ is expressed by Equation (18), and represented by the thin line in the bottom exactly same as the previous explanation. Figure $8 \mathrm{~b}$ shows a flow chart to estimate the line resistance. The process to obtain the estimated value is exactly same as the previous one.

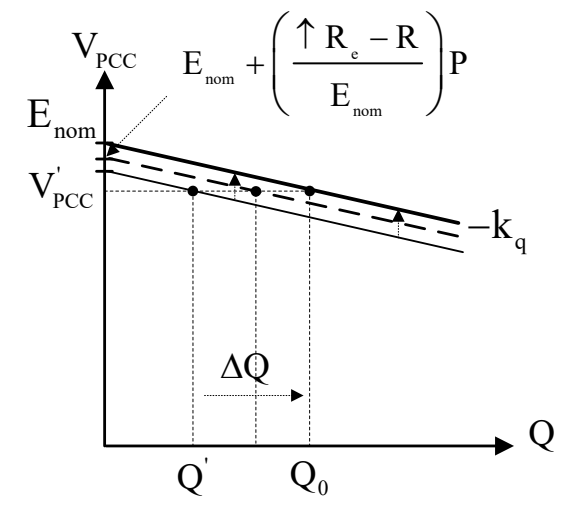

(a)

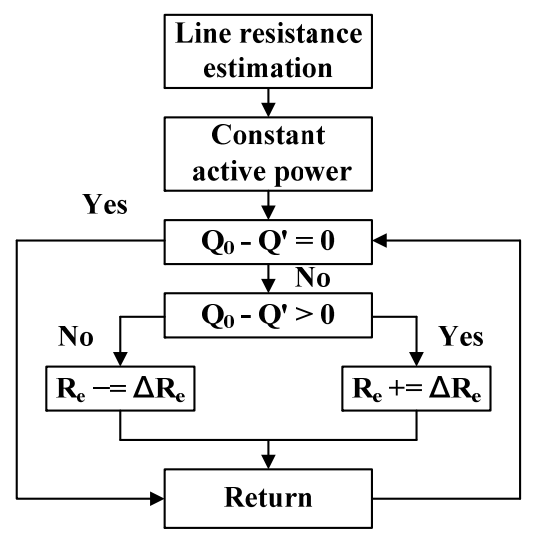

(b)

Figure 8. Algorithm for line resistance estimation: (a) Principle; (b) Estimation flow.

Figure 9 shows simulation results to estimate the line impedance using the proposed method assuming that the actual line impedance is $\mathrm{z}=0.1+\mathrm{j} 0.1885$. From $2 \mathrm{~s}$ to $9.5 \mathrm{~s}$, the active power $\mathrm{P}$ is set 0 and $Q$ is changed arbitrary. After $10.5 \mathrm{~s}$, the active power $P$ is set $5 \mathrm{~kW}$, and $Q$ is changed arbitrary. According to the simulation results shown in Table 1, the proposed algorithm is confirmed to be effective for estimating the line impedance.

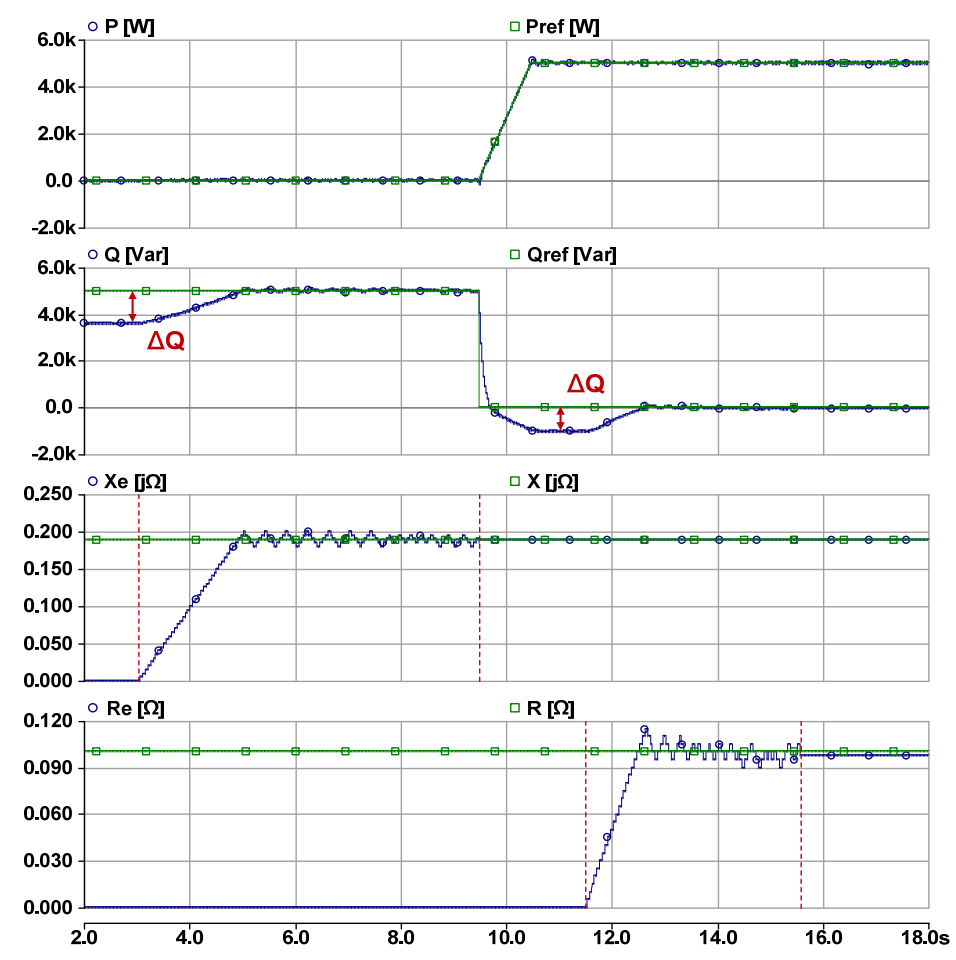

Figure 9. Simulation results for estimating line reactance and resistance estimation. 
Table 1. Line impedance estimation results.

\begin{tabular}{lccc}
\hline Parameter & Actual Value & Estimated Value & Error [\%] \\
\hline Resistance & $0.1(\Omega)$ & $0.0975(\Omega)$ & 2.5 \\
Reactance & $0.1885(\mathrm{j} \Omega)$ & $0.1880(\mathrm{j} \Omega)$ & 0.26 \\
\hline
\end{tabular}

\section{Voltage Control Design}

Figure 10a shows the power circuit of voltage source converter including coupling inductor and filter capacitor. Figure 10b shows a configuration of the output voltage control in which the current control is nested in the voltage control. In the current control, the coupling inductor is cross-coupled with each other, while the filter capacitor is cross-coupled with each other in the voltage control [31].

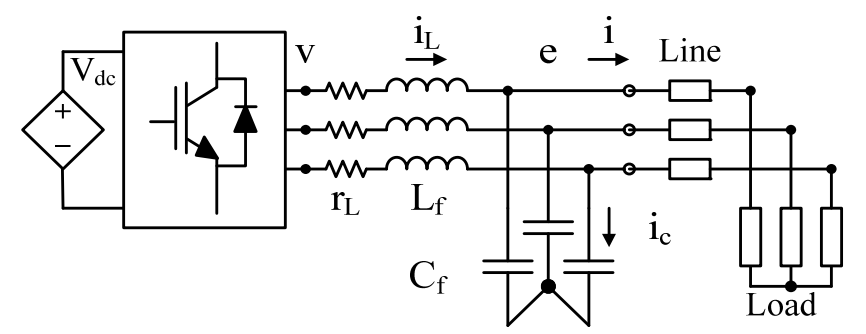

(a)

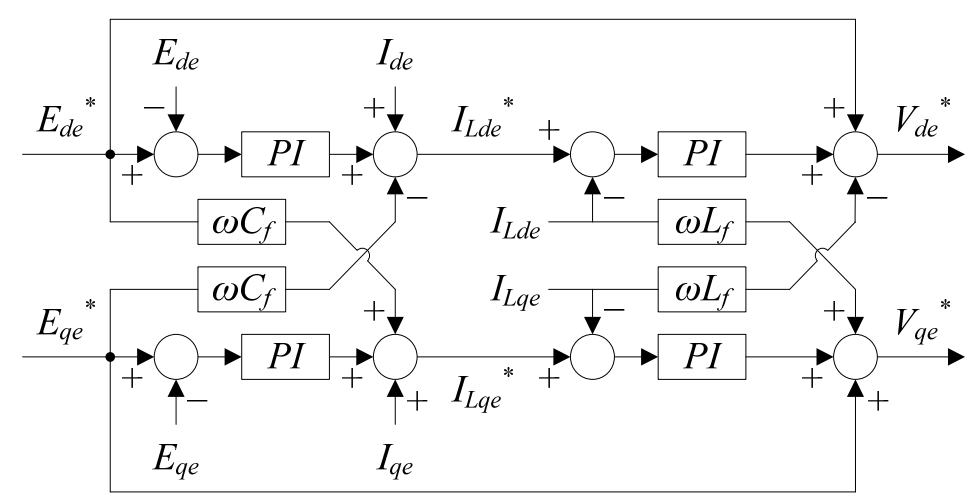

(b)

Figure 10. Voltage source converter and its voltage control. (a) Equivalent circuit for 3-phase inverter; (b) Output voltage control.

Figure 11 shows a simplified diagram for the voltage control loop which includes the current control loop inside.

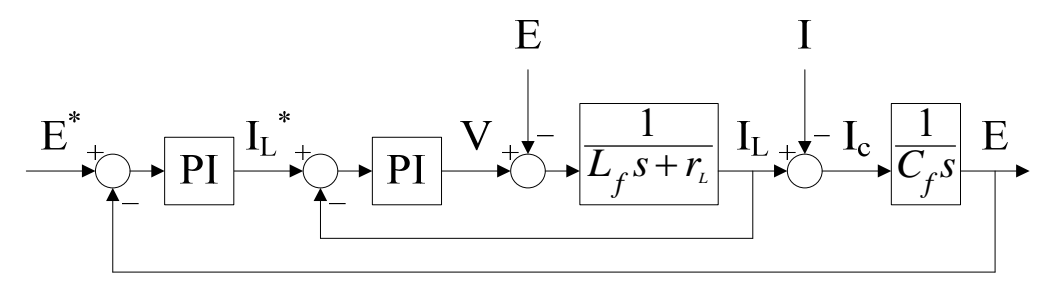

Figure 11. Block diagram for simplified voltage control. 
The closed-loop transfer function for the current control is represented by the following equation:

$$
G_{c c}(s)=\frac{I_{L}}{I_{L}^{*}}=\frac{\frac{K_{P C}}{L_{f}} s+\frac{K_{i c}}{L_{f}}}{s^{2}+\frac{K_{p c}}{L_{f}} s+\frac{K_{i c}}{L_{f}}}=\frac{\omega_{c}}{s+\omega_{c}}
$$

This equation can be rearranged as the following equation by defining the relationship of equation:

$$
\begin{aligned}
& \frac{\mathrm{r}_{\mathrm{L}}}{\mathrm{L}_{\mathrm{f}}}=\frac{\mathrm{K}_{\mathrm{ic}}}{\mathrm{K}_{\mathrm{pc}}} \\
& \omega_{\mathrm{c}}=\frac{\mathrm{K}_{\mathrm{pc}}}{\mathrm{L}_{\mathrm{f}}}
\end{aligned}
$$

where, $\omega_{C}$ is roughly determined by $1 / 10$ of the control frequency.

The closed-loop transfer function for the current control is represented by the following equation:

$$
G_{V C}(s)=\frac{E}{E^{*}}=\frac{\frac{\omega_{c}}{C_{f}}\left(s+\frac{K_{i v}}{K_{p v}}\right)}{s^{3}+\omega_{c} s^{2}+\frac{\omega_{c} K_{P V}}{C_{f}} s+\frac{\omega_{C} K_{i v}}{C_{f}}}
$$

The value of $\mathrm{K}_{\mathrm{pv}}$ and $\mathrm{K}_{\mathrm{iv}}$ can be defined so that the steady state error is less than $1 \%$ of the reference value and the settling time is also determined within $1 \%$ of the steady state error for the step response. Figure 12 shows the step response for the designed voltage controller and the tracking performance for the reference voltage.

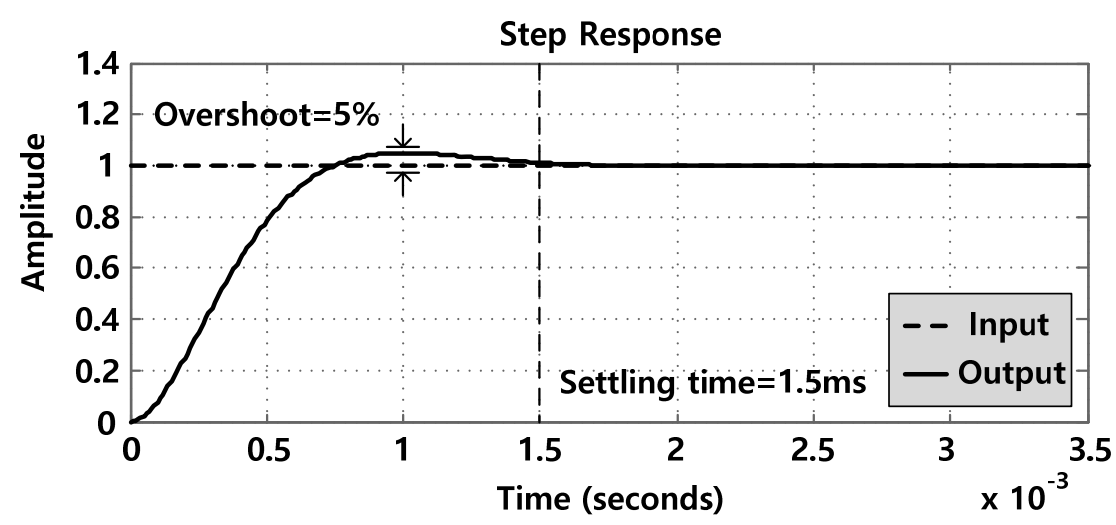

(a)

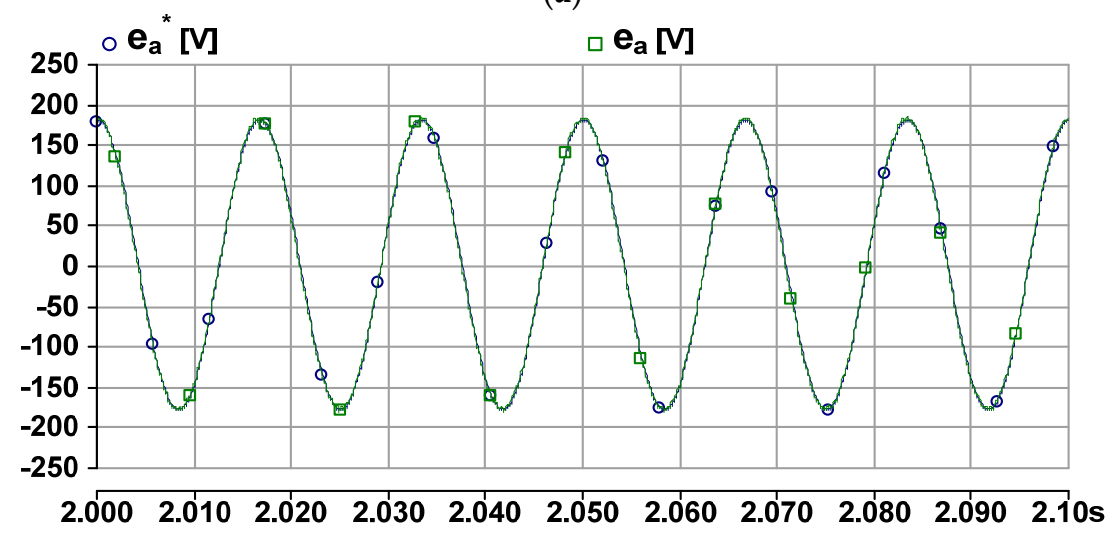

(b)

Figure 12. Performance analysis of voltage control: (a) Step response; (b) Voltage control. 
Figure 13 shows a block diagram to describe the proposed droop control and the control of inverter output voltage. Since the proposed droop control uses d-axis and q-axis currents on the synchronous reference frame, the voltage drop due to the line impedance can be simply compensated by feed-forward manner.

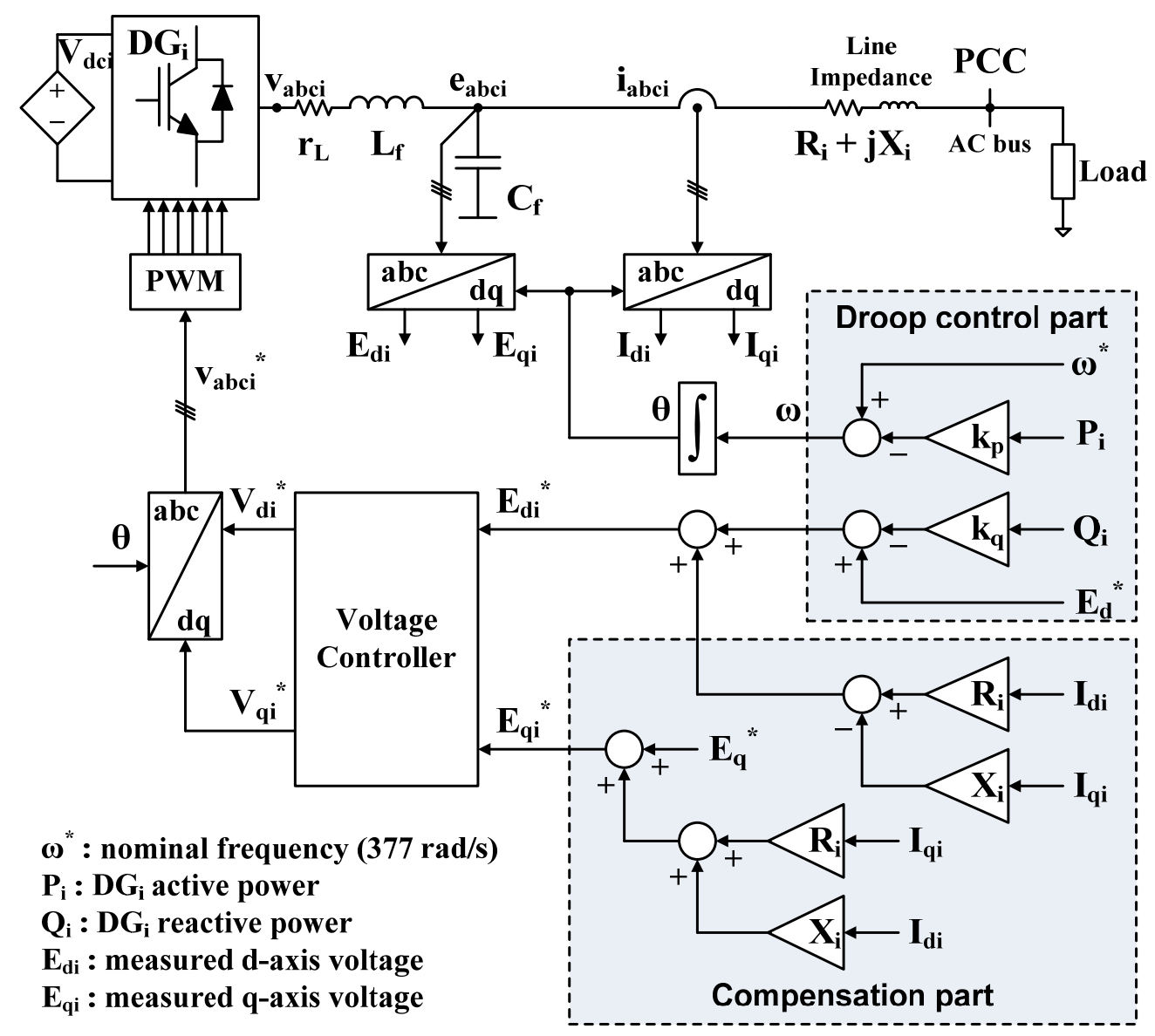

Figure 13. Entire structure of proposed droop control.

\section{Computer Simulation}

Computer simulations were conducted for two parallel-connected DGs through unequal line impedances shown in Figure 14. The power circuit was represented with built-in library model while the proposed control was represented with user-defined model programmed with $C$ code. Table 2 shows the circuit and control parameters for the DGs. The maximum frequency fluctuation was set to $\pm 1 \%$, and the voltage fluctuation was set to $\pm 3 \%$, according to the frequency and voltage regulation of utility. 


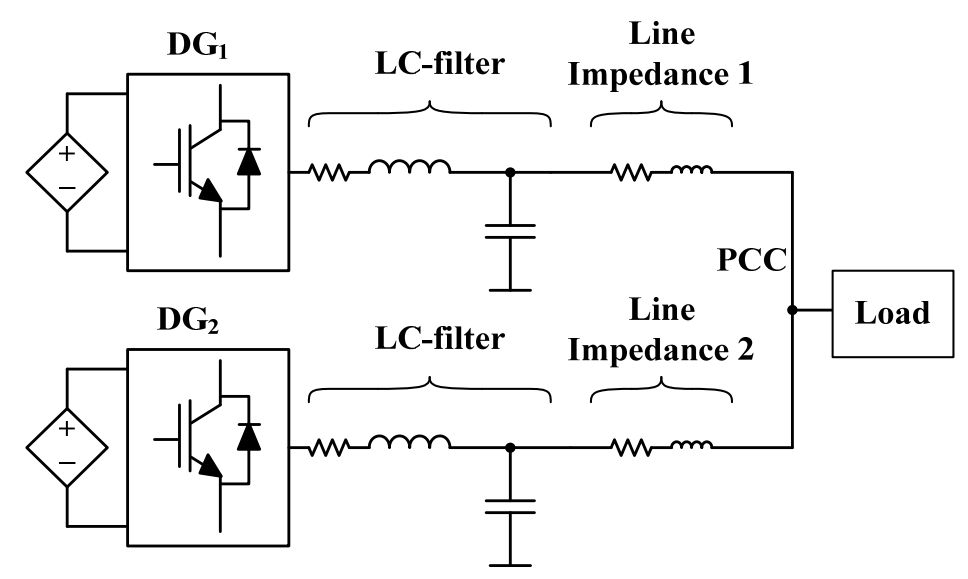

Figure 14. Circuit for two parallel DGs.

Table 2. Circuit and control parameters.

\begin{tabular}{cc}
\hline Items & $\mathbf{D G}_{\mathbf{1 , 2}}$ \\
\hline Rated power & $5(\mathrm{kVA})$ \\
Frequency droop coefficient $\mathrm{k}_{\mathrm{p}}$ & 0.0008 \\
Voltage droop coefficient $\mathrm{k}_{\mathrm{q}}$ & 0.001 \\
DC link (lithium-polymer battery) & $336 \sim 470.4(\mathrm{~V})$ \\
PCC voltage & $220 \mathrm{Vrms}$ \\
Filter $\mathrm{L}_{\mathrm{f}}$ & $1(\mathrm{mH})$ \\
Filter $\mathrm{C}_{\mathrm{f}}$ & $20(\mathrm{uF})$ \\
\hline
\end{tabular}

In the simulations, the existing droop control and the proposed droop control were compared with each other for two types of line such as pure inductance and inductance with resistance to analyze the reactive power sharing characteristics. Table 3 shows two cases for the different line impedances. In case 1 , only the line inductance has different values while in case 2 , both line resistance and inductance have different values.

Table 3. Scenario of line impedance and simulation.

\begin{tabular}{ccc}
\hline Case 1 & Line Impedance 1 & $0.0+\mathrm{j} 0.1885(\Omega)$ \\
& Line Impedance 2 & $0.0+\mathrm{j} 0.3770(\Omega)$ \\
\hline \multirow{2}{*}{ Case 2 } & Line Impedance 1 & $0.1+\mathrm{j} 0.1885(\Omega)$ \\
& Line Impedance 2 & $0.2+\mathrm{j} 0.3770(\Omega)$ \\
\hline
\end{tabular}

Table 4 shows simulation scenario in which the active and reactive powers of load changes with step manner for $10 \mathrm{~s}$ of duration. Figure 15 shows the simulation results for the active and reactive power sharing with the existing droop control and the proposed droop control for Case 1.

Table 4. Simulation Scenario.

\begin{tabular}{ccccc}
\hline & 0-10 s & 10-20 s & 20-30 s & 30-40 s \\
\hline PL [kW] & 5 & 10 & 8 & 4 \\
QL & 0 & 0 & 6 & 3 \\
[kVar] & & & & \\
\hline
\end{tabular}



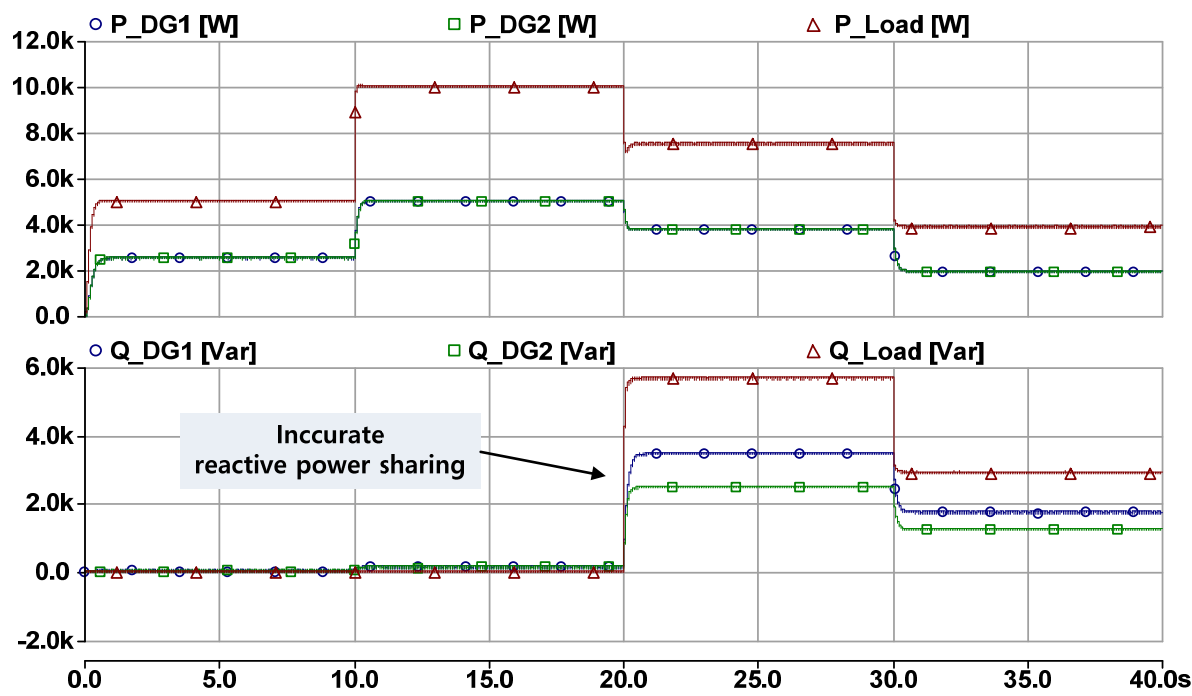

(a)
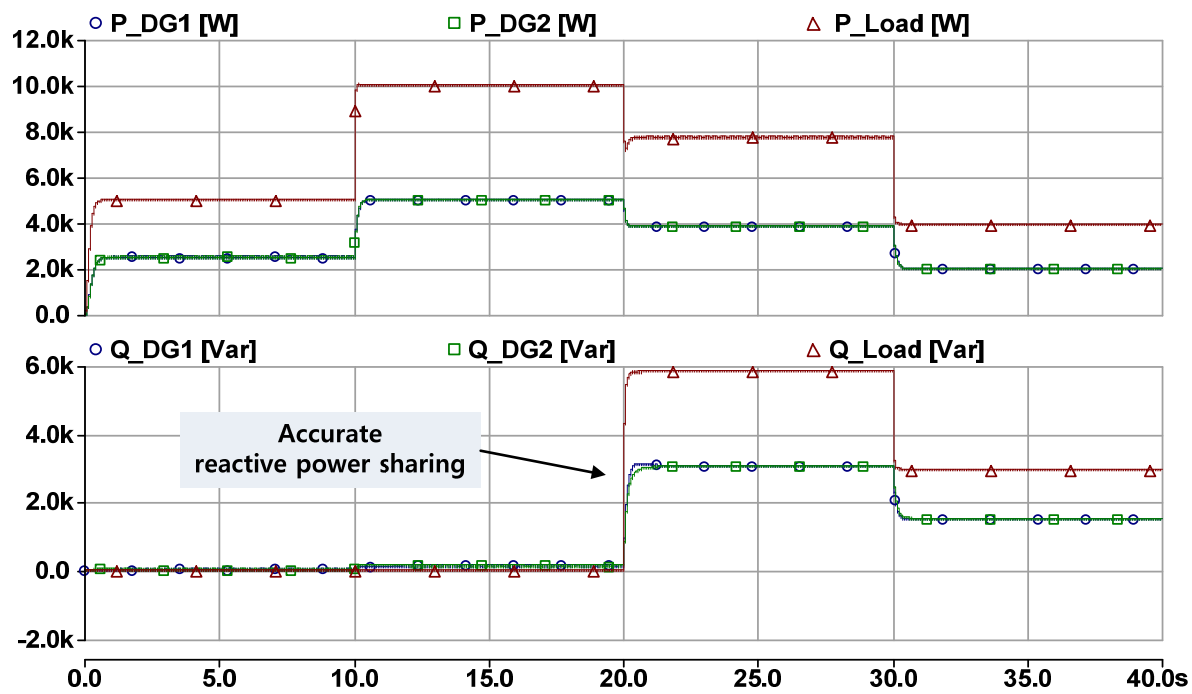

(b)

Figure 15. Simulation results of active and reactive power sharing for Case 1: (a) Existing droop (b) Proposed droop.

Although circulating current are not generated in the active power sharing, different voltage drops occur in the 20-40 s section when purely reactive power is supplied so that accurate reactive power sharing is not conducted, as shown in Figure 15a.

However, in case of the proposed droop control as shown in Figure 15b, the voltage drop due to the q-axis current is simply compensated by the product of the line inductance and the q-axis current $\mathrm{I}_{\mathrm{q}}$. The accurate reactive power sharing can be conducted even in the $20-40 \mathrm{~s}$ section.

Figure 16 shows the simulation results for the active and reactive power sharing with the existing droop control and the proposed droop control for Case 2. When the existing droop control is used as shown in Figure 16a, it can be seen that the voltage differences are caused by the voltage drop due to the d-axis current and the line's resistance, and the q-axis current and the line's inductance. So, the reactive power sharing is not accurately conducted. 

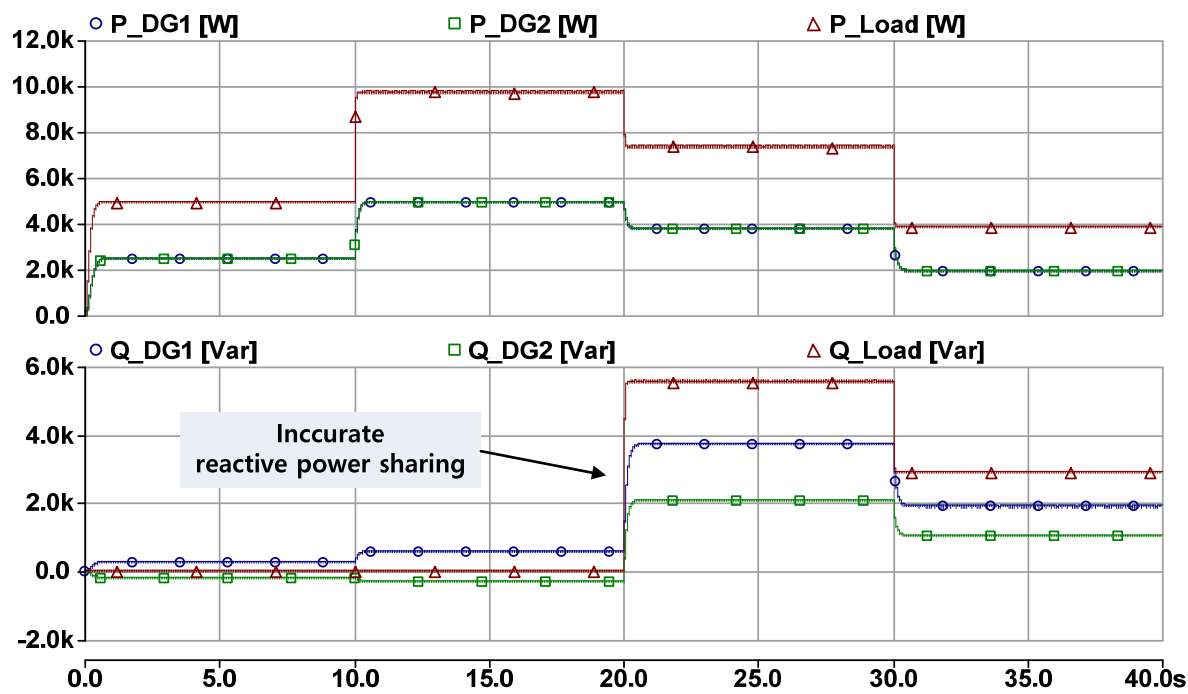

(a)
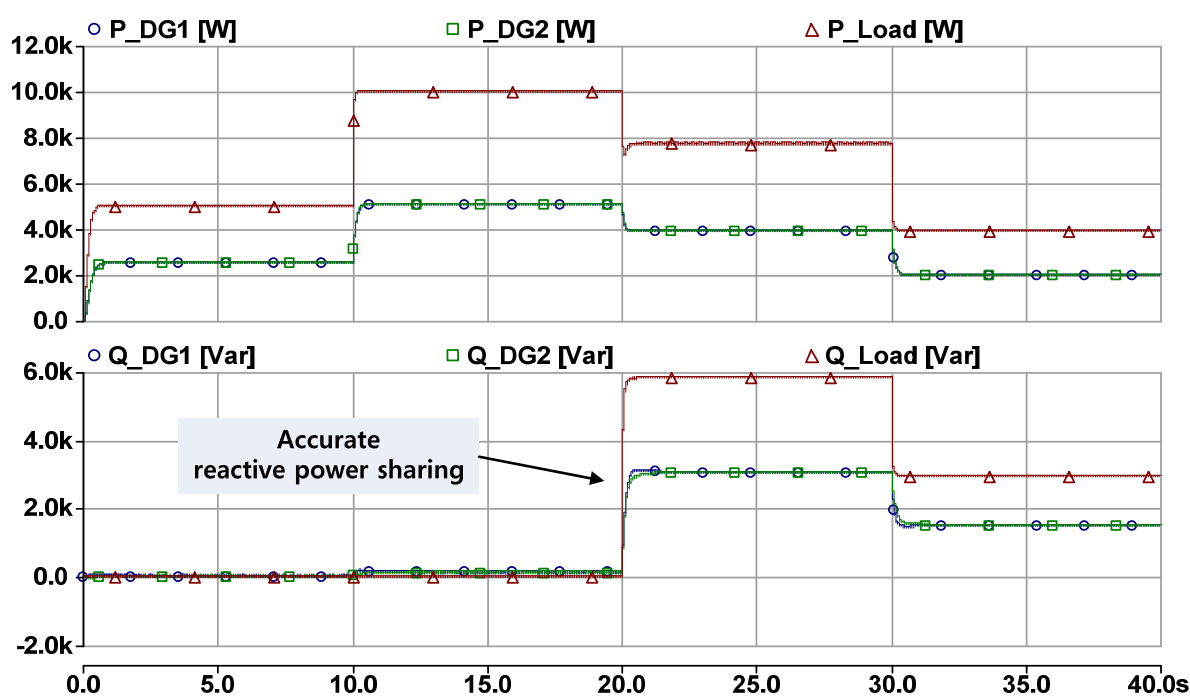

(b)

Figure 16. Simulation Results of Active and Reactive Power Sharing for Case 2: (a) Existing droop (b) Proposed droop.

However, if the proposed droop control is applied, as shown by the results in Figure 16b, the active and reactive power sharing will be accurately conducted. By using the proposed droop control applied on the synchronous coordinate system, the difference due to voltage drop can be compensated through calculating the product of $d-q$ axis current $I_{d}, I_{q}$ and the line impedance.

Figure 17 shows the line currents of two parallel-operated DGs when they supply active and reactive powers through unequal line impedances. Both currents have different magnitude and phase in Figure 17a, which generates circulating current. On the contrary, both currents have same magnitude and phase in in Figure 17b, which eliminates the circulating current. 


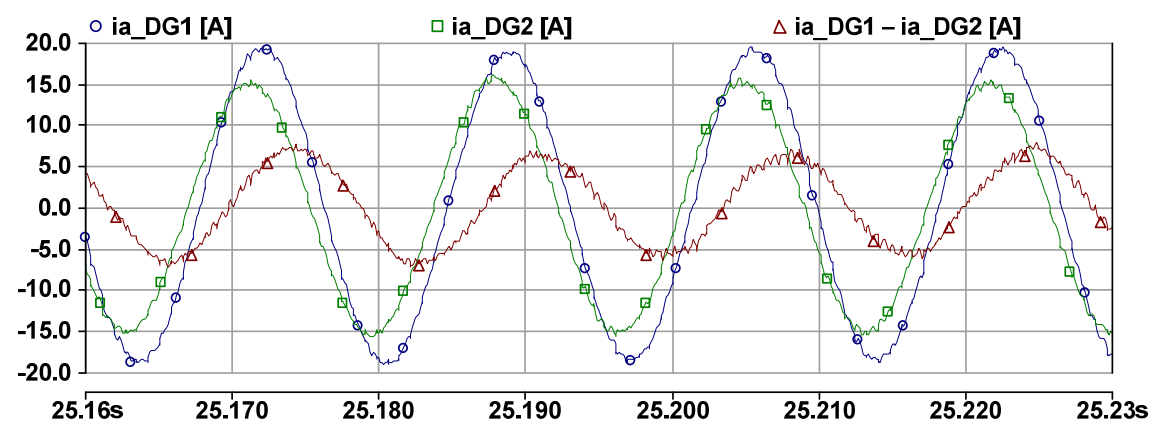

(a)

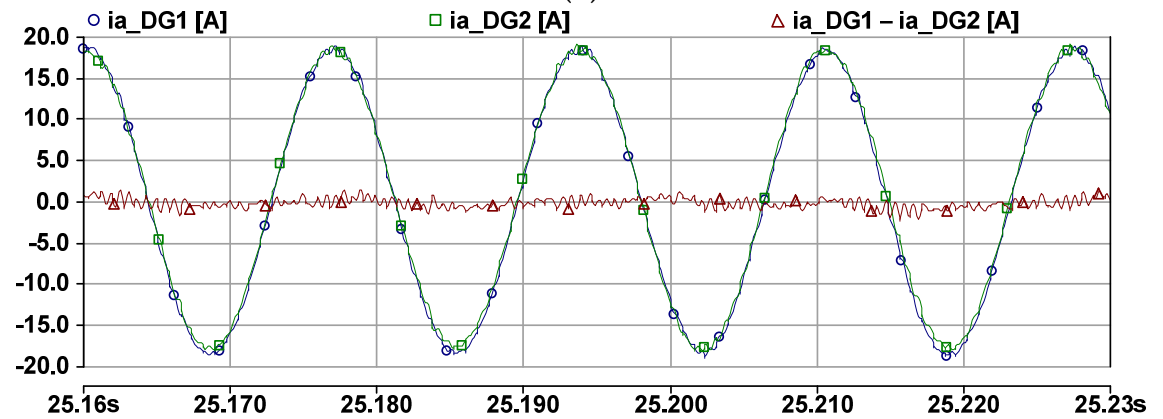

(b)

Figure 17. Simulation results of DG currents and circulating current: (a) Existing droop (b) Proposed droop.

\section{Experimental Verification}

A hardware test set was built in the lab to verify the performance of proposed droop control experimentally as shown in Figure 18. DG is represented by an energy storage system which has a 3-phase inverter with lithium-polymer battery in the DC terminal. The line is represented by a series-connected R-L circuit. The same circuit and control parameters in Table 2 were used to compare the experimental results with the simulation results. Figure 19 shows the active and reactive power in the existing droop control and the proposed droop control for case 1. Circulating current is generated in the 20-40 s section due to the voltage drop differences occurring when the reactive power is supplied. In Figure 19a, it can be seen that the reactive power sharing is not conducted.

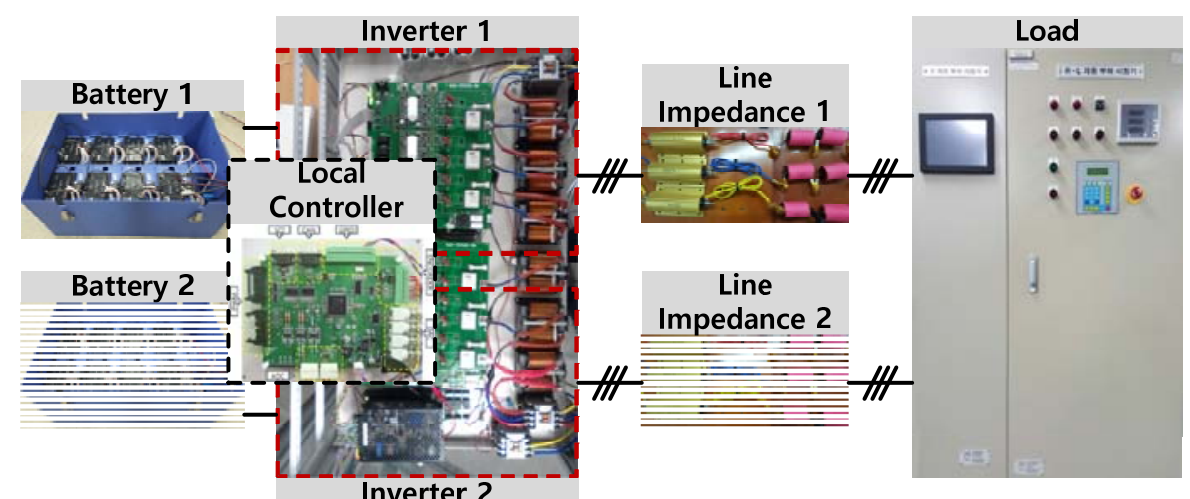

Figure 18. Configuration of hardware test set-up. 


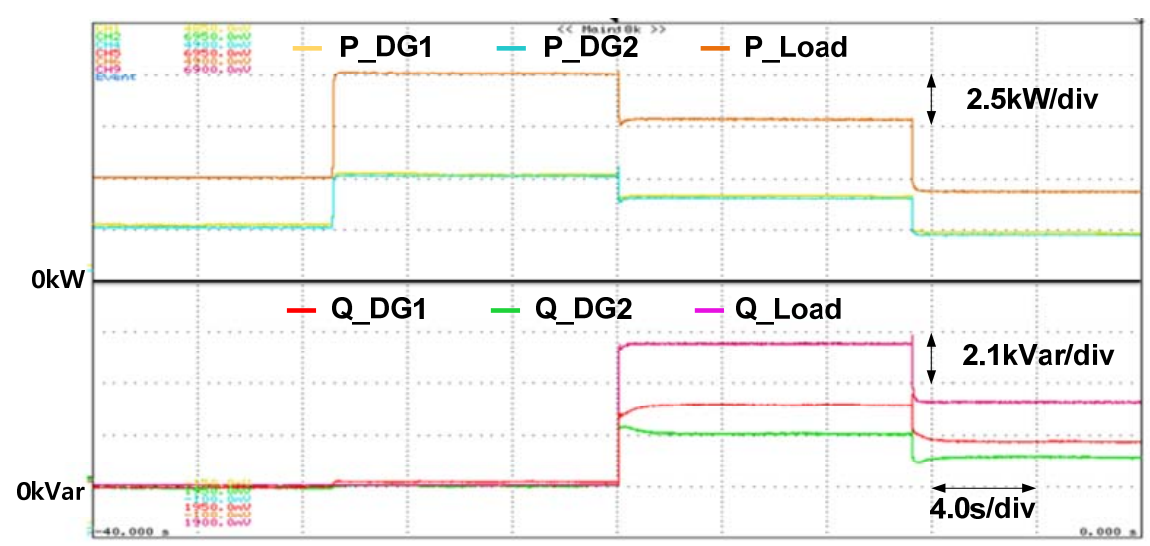

(a)

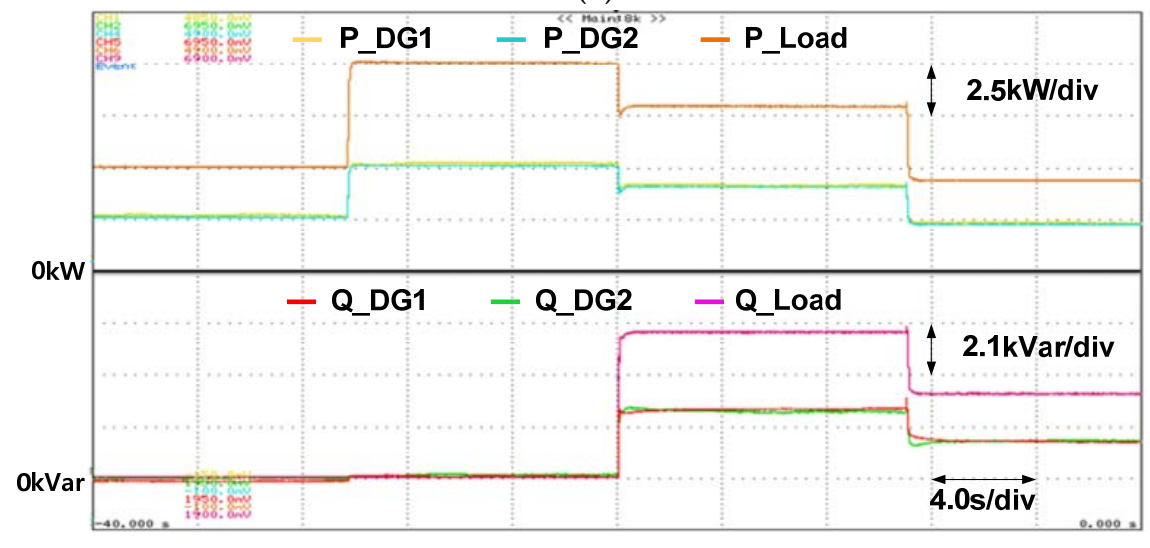

(b)

Figure 19. Experimental results of active and reactive power for Case 1: (a) Existing droop (b) Proposed droop.

However, in the case of the proposed droop control, the voltage drop caused by the q-axis current and the inductance is feed-forward compensated to the reference voltage value in the V-Q droop control equation. As shown in Figure 19b, the accurate reactive power sharing is conducted even in the 20-40 s section when the reactive power is supplied.

Figure 20a shows the experimental results of active and reactive power sharing for Case 2 by applying the existing droop control. The reactive power sharing cannot be carried out due to the unequal voltage drop in the line impedances.

However, as shown in Figure 20b, the voltage drop caused by the q-axis current and the line inductance, is finally compensated to the reference voltage in the V-Q droop control equation separately so that reactive power sharing can be improved. 


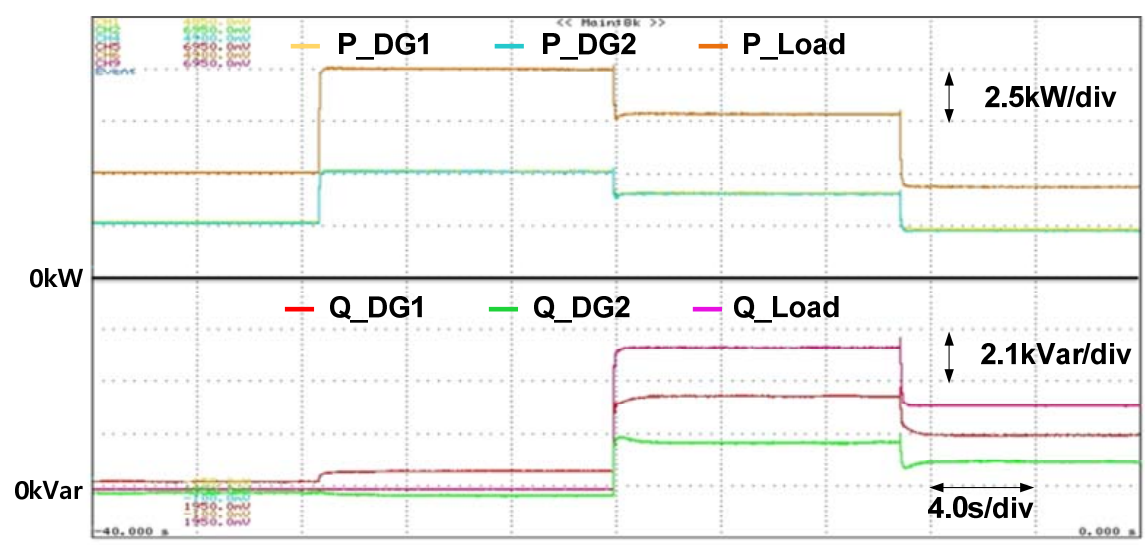

(a)

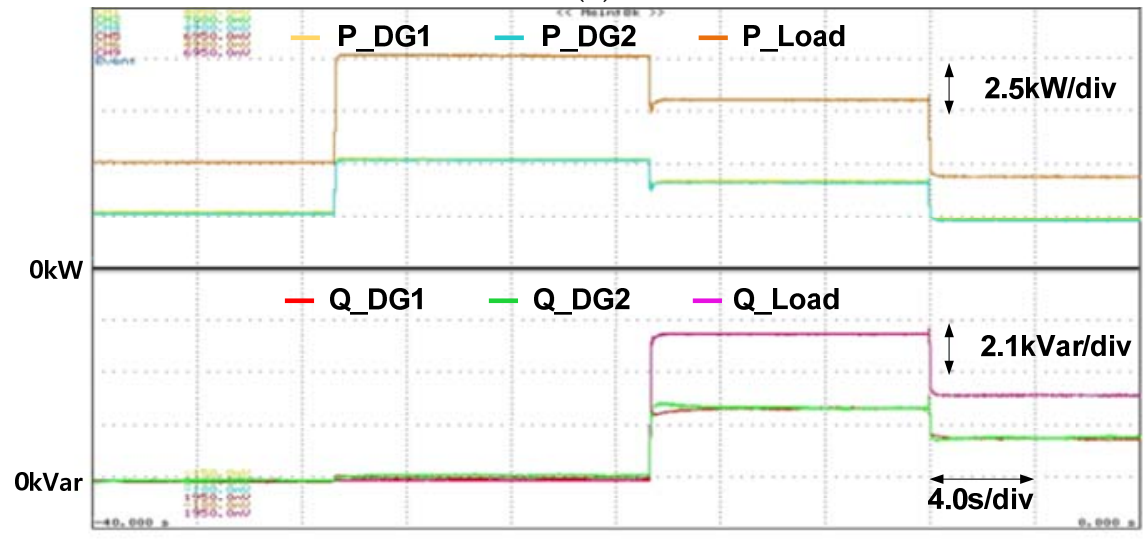

(b)

Figure 20. Experimental results of active and reactive power for Case 2: (a) Existing droop; (b) Proposed droop.

Figure 21 shows the line currents of two parallel-operated DGs when they supply active and reactive powers through unequal line impedances. Both currents have different magnitude and phase in Figure 21a, which generates circulating current. On the contrary, both currents have same magnitude and phase in in Figure 21b, which eliminates the circulating current.

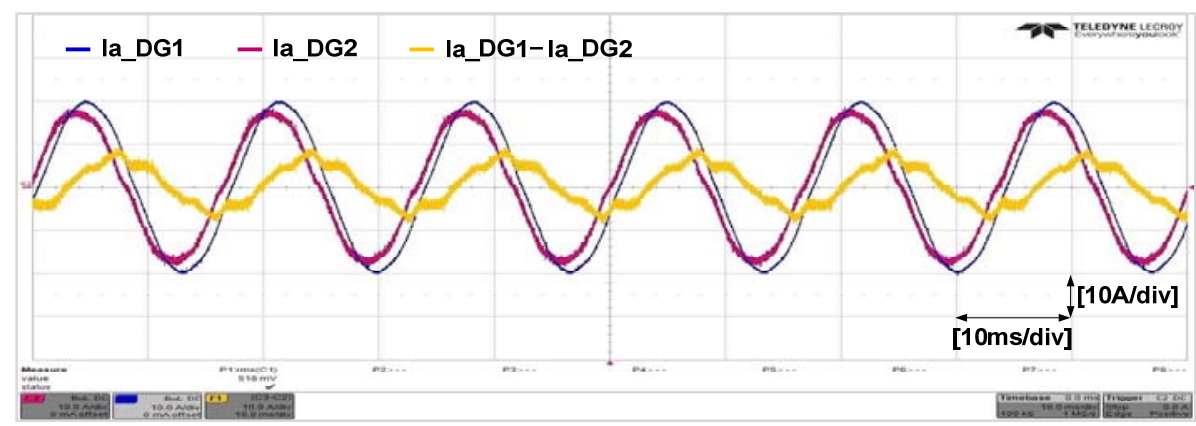

(a)

Figure 21. Cont. 


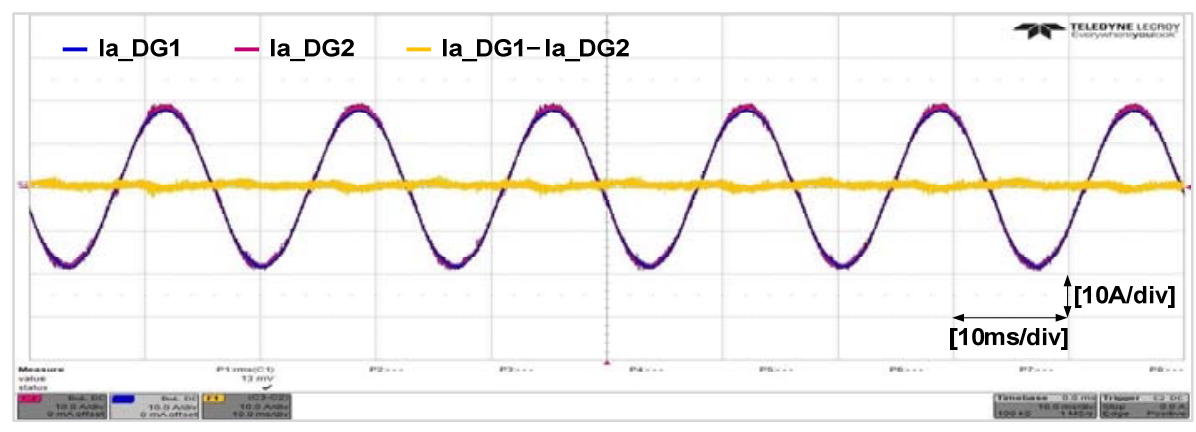

(b)

Figure 21. Experimental Results of DG currents and Circulating current: (a) Existing droop (b) Proposed droop.

\section{Conclusions}

This paper proposes a new reactive-power sharing scheme to reduce the circulating current when two inverter-based DGs operate in parallel through unequal line impedances in islanded microgrids. The proposed droop control compensates the voltage drop differences due to the unequal line impedance to the reference voltage of the V-Q droop equation through the feed-forward path.

The power decoupling on the $\mathrm{d}$-q synchronous coordinate makes it easier to calculate the voltage drop due to the unequal line impedance. The accurate gain of the proportional integral control was set through modelling the system to enhance the stability and dynamic performance. The circulating current due to the unequal line impedance was analyzed for the proposed droop control through computer simulations and hardware experiments. Through this process, it was confirmed that the proposed droop control suppresses the circulating current.

Acknowledgments: This research was supported by the Korea Electric Power Corporation (Grant number: R15XA03-46), and the National Research Foundation (NRF) grant funded by the Korea Ministry of Science, ICT and Future Planning (NRF-2015R1A2A2A01004102).

Author Contributions: Jae-Hyuk Kim, Yoon-Seok Lee, and Hyun-Jun Kim proposed the original idea, and carried out computer simulations and experiments. Byung-Moon Han wrote the full manuscript and supervised the simulations and experiments.

Conflicts of Interest: The authors declare no conflict of interest.

\section{Nomenclature}

P Active power

Q Reactive power

$\mathrm{k}_{\mathrm{p}} \quad$ Droop coefficient of frequency

$\mathrm{k}_{\mathrm{q}} \quad$ Droop coefficient of magnitude

$\omega^{*} \quad$ Nominal frequency of PCC

$\mathrm{E}^{*} \quad$ Nominal voltage of PCC

$\omega \quad$ Output voltage frequency

E Output voltage magnitude

$E_{d} \quad$ Output voltage (d-axis)

$\mathrm{E}_{\mathrm{q}} \quad$ Output voltage (q-axis)

$\mathrm{E}_{\mathrm{d}}^{*} \quad$ Output voltage reference (d-axis)

$\mathrm{E}_{\mathrm{q}}^{*} \quad$ Output voltage reference (q-axis)

$\mathrm{V}_{\mathrm{L}_{-} \mathrm{d}} \quad$ Load voltage (d-axis)

$\mathrm{V}_{\mathrm{L}_{\mathrm{q}} \mathrm{q}} \quad$ Lad voltage (q-axis)

$\mathrm{V}_{\mathrm{L}} \quad$ Magnitude of load voltage

$\mathrm{V}_{\text {PCC_d }} \quad$ PCC voltage (d-axis) 


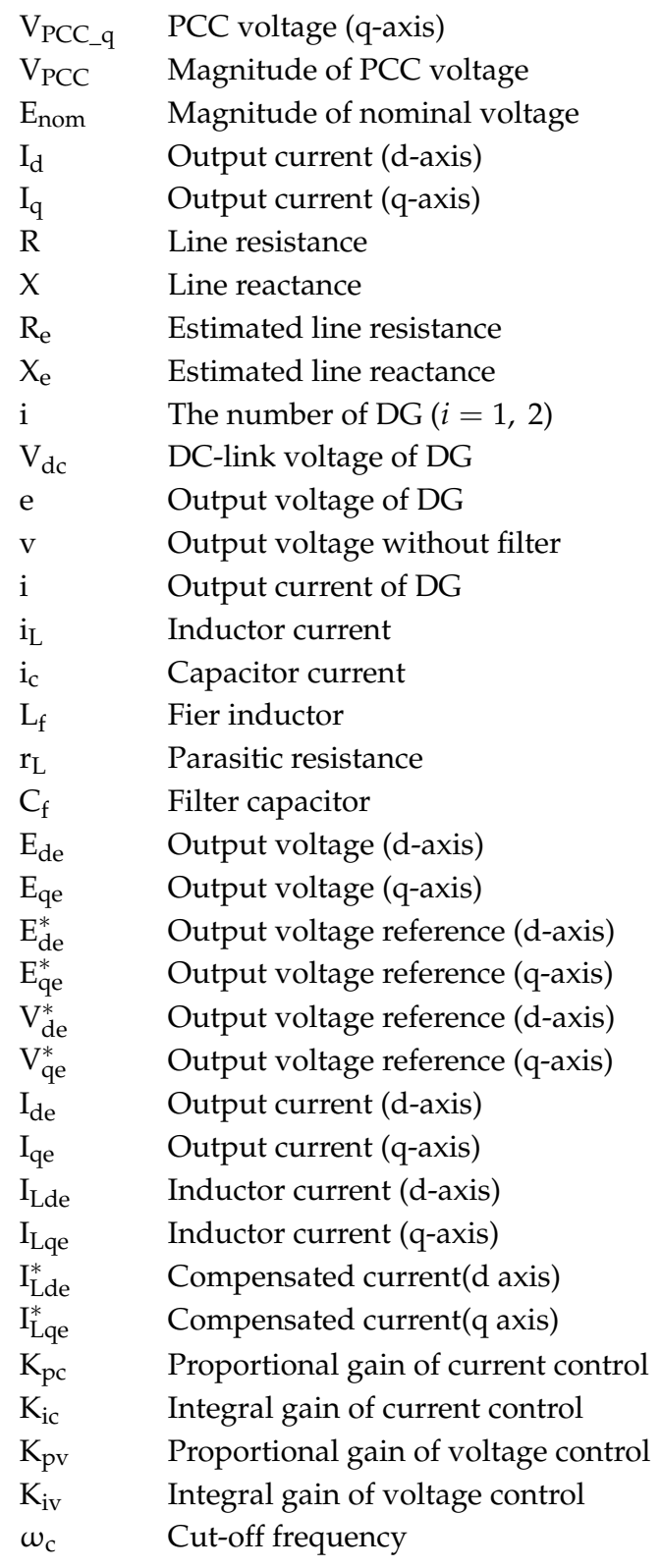

\section{References}

1. Li, Y.W.; Kao, C.N. An accurate power control strategy for power electronics-interfaced distributed generation units operating in a low voltage Multi bus microgrid. IEEE Trans. Power Electron. 2009, 24, 2977-2988.

2. Mahmud, M.; Hossain, M.; Pota, H.; Oo, A. Robust nonlinear distributed controller design for active and reactive power sharing in islanded microgrid. IEEE Trans. Energy Convers. 2014, 29, 893-903. [CrossRef]

3. Souza, W.; Mendes, M.; Lopes, L. Power sharing control strategies for a three-phase microgrid in different operating condition with droop control and damping factor investigation. IET Proc. Renew. Power Gener. 2015, 9, 831-839. [CrossRef]

4. Guerrero, J.; de Vicuna, L.; Matas, J.; Castilla, M.; Miret, J. A wireless controller to enhance dynamic performance of parallel inverters in distributed generation system. IEEE Trans. Power Electron. 2004, 19, 1205-1213. [CrossRef]

5. Kahrobaeian, A.; Mohamed, Y.A.R.I. Networked-based hybrid distributed power sharing and control for islanded microgrid systems. IEEE Trans. Power Electron. 2015, 30, 603-617. [CrossRef]

6. Shafiee, Q.; Guerrero, J.M.; Vasquez, J. Distributed secondary control for islanded microgrids-A novel approach. IEEE Trans. Power Electron. 2014, 29, 1018-1031. [CrossRef] 
7. Liang, H.; Choi, B.J.; Zhuang, W. Stability enhancement of decentralized inverter control through wireless communications in microgrids. IEEE Trans. Smart Grid 2013, 4, 321-331. [CrossRef]

8. Mohamed, Y.; El-Saadany, E. Adaptive decentralized droop controller to preserve power sharing stability of paralleled inverters in distributed generation microgrids. IEEE Trans. Power Electron. 2008, 23, 2806-2816. [CrossRef]

9. Majumder, R.; Ghosh, A.; Ledwich, G.; Zare, F. Operation and control of hybrid microgrid with angle droop controller. In Proceedings of the 2010 IEEE Region 10 Conference, Fukuoka, Japan, 21-24 November 2010; pp. 509-515.

10. Chiang, H.C.; Jen, K.K.; You, G.H. Improved droop control method with precise current sharing and voltage regulation. IET Power Electron. 2016, 9, 789-800. [CrossRef]

11. Hua, H.; Liu, Y.; Sun, Y.; Su, M.; Guerrero, J.M. An improved droop control strategy for reactive power sharing in islanded microgrid. IEEE Trans. Power Electron. 2015, 30, 3133-3141.

12. Brabandere, K.D.; Bolsens, B.; Keybus, J.V.D.; Woyte, A.; Driesen, J.; Belmans, R. A voltage and frequency droop control method for parallel inverters. IEEE Trans. Power Electron. 2007, 22, 1107-1115. [CrossRef]

13. Han, Y.; Li, H.; Shen, P.; Coelho, E.; Guerrero, J. Review of Active and Reactive Power Sharing Strategies in Hierarchical Controlled Microgrids. IEEE Trans. Power Electron. 2017, 32, 2427-2451. [CrossRef]

14. Mahmood, H.; Michaelson, D.; Jiang, J. Reactive power sharing in islanded microgrids using adaptive voltage droop control. IEEE Trans. Smart Grid 2015, 6, 3052-3060. [CrossRef]

15. He, J.W.; Li, Y.W. An enhanced microgrid load demand sharing strategy. IEEE Trans. Power Electron. 2012, 27, 3984-3995. [CrossRef]

16. Li, P.; Wang, X.B.; Lee, W.J.; Xu, D. Dynamic power conditioning method of microgrid via adaptive inverse control. IEEE Trans. Power Deliv. 2015, 30, 906-913. [CrossRef]

17. Yao, W.; Chen, M.; Matas, J.; Guerrero, J.M.; Qian, Z.M. Design and analysis of the droop control method for parallel inverters considering the impact of the complex impedance on the power sharing. IEEE Trans. Ind. Electron. 2011, 58, 576-588. [CrossRef]

18. Zhong, Q. Robust Droop Controller for Accurate Proportional Load Sharing among Inverters Operated in Parallel. IEEE Trans. Ind. Electron. 2013, 60, 1281-1290. [CrossRef]

19. You, Z.; Liu, J.; Zhang, X.; Wang, X. A Decoupled and Adaptive Power Sharing Strategy Based on Droop Method for Parallel Inverters. In Proceedings of the APEC 2014, Fort Worth, TX, USA, 16-20 March 2014.

20. Lee, C.; Chu, C.; Cheng, P. A New Droop Control Method for the Autonomous Operation of Distributed Energy Resource Interface Converters. IEEE Trans. Power Electron. 2013, 28, 1980-1993. [CrossRef]

21. Guerrero, J.; Matas, J.; de Vicuna, L.; Castila, M.; Miret, J. Decentralized control for parallel operation of distributed generation inverters using resistive impedance. IEEE Trans. Ind. Electron. 2007, 54, 994-1004. [CrossRef]

22. He, J.W.; Li, Y.W. Analysis, Design, and Implementation of Virtual Impedance for Power Electronics Interfaced Distributed Generation. IEEE Trans. Ind. Appl. 2011, 47, 2525-2538. [CrossRef]

23. Mahmood, H.; Michaelson, D.; Jiang, J. Accurate reactive power sharing in an islanded microgrid using adaptive virtual impedance. IEEE Trans. Power Electron. 2015, 30, 1605-1617. [CrossRef]

24. Guo, Q.; Wu, H.; Lin, L.; Bai, Z.; Ma, H. Secondary Voltage Control for Reactive Power Sharing in an Islanded Microgrid. J. Power Electron. 2016, 16, 329-339. [CrossRef]

25. Tuladhar, A.; Jin, H.; Unger, T.; Mauch, K. Control of parallel inverters in distributed AC power systems with consideration of line impedance effect. IEEE Trans. Ind. Appl. 2000, 36, 131-138. [CrossRef]

26. Zhang, X.; Liu, J.; You, Z.; Liu, T. Study on the Influence of Distributed Lines to Parallel Inverter Systems Adopting the Droop Control Method. J. Power Electron. 2013, 13, 701-711. [CrossRef]

27. Sumner, M. Impedance measurement for improved power quality-Part 1: The measurement technique. IEEE Trans. Power Deliv. 2004, 19, 1442-1448. [CrossRef]

28. Roinila, T.; Vilkko, M.; Sun, J. Broadband methods for on-line grid impedance measurement. In Proceedings of the IEEE Energy Conversion Congress \& Exposition (ECCE 2013), Denver, CO, USA, 15-19 September 2013; pp. 3003-3010.

29. Hoffmann, N.; Fuchs, F. Minimal Invasive Equivalent Grid Impedance Estimation in Inductive-Resistive Power Networks using Extended Kalman Filter. IEEE Trans. Power Electron. 2014, 29, 631-641. [CrossRef] 
30. Shi, Y.; Su, J.; Li, J.; Hao, X. Line Impedance Measure Method for Microgrid. In Proceedings of the International Power Electronics and Application Conference and Exposition, Shanghai, China, 5-8 November 2014; pp. 378-383.

31. Han, B.; Bae, B.; Kim, H.; Baek, S. Combined operation of unified power-quality conditioner with distributed generation. IEEE Trans. Power Deliv. 2006, 21, 330-338. [CrossRef] 